\title{
RESENHA:
}

\section{A Constituição do Personagem a Partir Discurso do EU ILUDIDO: IDENTIDADE, SOMBRA E VIOLÊNCIA INVISÍVEL}

O poder do discurso materno: Introdução à metodologia de construção da biografia humana. GUTMAN, Laura. Trad. Lizandra Magon de Almeida. 4. ed. São Paulo: Ágora, 2013

\section{Rafael da Silveira ${ }^{1}$}

A introdução à metodologia de construção da biografia humana coincide com a ciência subjetiva que analisa os processos psíquicos do indivíduo, que é a Psicanálise, que teve seu principal mentor e Pai da Psicanálise - Sigmund Freud - através de técnicas de associação livre para analisar as tramas do inconsciente, de suas fantasias, desejos, neuroses, dentre outros, em práticas que perduram até os dias atuais, ainda que na atualidade haja convergência de muitas outras teorias e metodologias, assim como infindáveis críticas ao método catártico freudiano.

Para constituição do personagem, nossa mãe ou mesmo a voz mais dominante do palco familiar - como o pai, tios e mesmo os avós - nos observam atentamente para então nos nomear a partir de mecanismos de projeção de sua própria imagem e visão de mundo, através da individualidade do ser-estar-sentir e agir no mundo, escolhendo palavras para nos descrever enquanto indivíduos que se inserem em inúmeras tramas familiares.

A partir de mecanismos de projeção, ou seja, da imagem que os seres humanos constituem de si mesmo e do outro, é que a autora utiliza a metáfora de que toda família funciona como um palco de peça de teatro, na medida em que são encenadas por personagens que terão seu roteiro desenhado na forma de mapas, inclusive utilizando roupas teatrais personificadas para o momento em que deve atuar/agir/ser de cada personagem.

\footnotetext{
${ }^{1}$ Mestrando (Aluno Temporário) na UFPE. É Psicanalista Clínico, Pós-graduado em Psicopedagogia Clínica e Institucional, em Neuropsicopedagogia e Graduado em Pedagogia. Pesquisador na área de Educação e saúde mental. É Professor-convidado Faculdade Alpha do Recife em 2019. E-mail: prof.rafael.silveira@gmail.com - Fone: (081) 9 9571-8328. ORCID: http://orcid.org/0000-0002-78659628.
} 
Isto é possível a partir da nomeação de personagens familiares que os indivíduos podem representar, e representam muito bem os papéis atribuídos por seus cuidadores, geralmente a mãe, até porque esses personagens são insistentemente reafirmados para que o indivíduo possa incorporá-los. A primeira impressão que fica é que parece algo razoavelmente normal para qualquer ser humano do ponto de vista de sua observabilidade e julgamento inicial, então se choramos a mais do que nossa mãe tolera, podemos ser nomeados como chorão, se houve irmãos que choraram menos que a expectativa esperada por ela, podem ser nomeados como tranquilos, e assim por diante, até porque as mães percebem desde muito cedo, a força e vitalidade, a temperança e o equilíbrio, assim como a sensibilidade que a criança possui em sua mais pura essência de ser-estar-sentir e agir no mundo.

O conceito de sombra perpassa a compreensão de que a criança recémchegada geralmente é vestida por um disfarce novo e disponível no palco da trama familiar, que pode ir se modificando ao longo do tempo, encontrados no baú da vida de forma bem variada, tais como: a virgem, a donzela, o pão-duro, o chefe, o salvador, os anjos, o cavalheiro, a bruxa, a má, o lobo, dentre outras infinidades de personagens possíveis que caracterizam as ações de um sujeito para desempenhar $(n)$ papeis.

O que desempenha o papel de lobo que come a avozinha no conto da Chapeuzinho Vermelho não pode ser bom porque deixaria de ser lobo, neste sentido, os personagens atribuídos a todos nós, desde que nascemos não dá conta do nosso ser integral em sua totalidade, porque nosso ser interior é muito mais ambivalente e rico, em todos os sentidos humanos possíveis, por isso, nenhum discurso materno poderá ser capaz de proferir a totalidade em essência de uma criança.

A metodologia de construção da biografia humana caminha juntamente com perspectivas teórico-práticas freudianas, no sentido de confirmar a ambivalência de vários sentimentos humanos e mecanismos de defesa, como por exemplo, quando sentimos raiva de nossa mãe, inibimos tal sentimento porque dependemos dela para nos abrigar e amparar e em troca disto, mesmo que soframos violências diversas, como o desamparo emocional e afetivo, acabamos gerando mecanismos para nos fazer crer que não acontece aquilo que realmente acontece.

$\mathrm{Na}$ metodologia analisada, para detectar o discurso do eu iludido, onde quase sempre aparece o discurso da mãe são realizadas perguntas bem específicas relacionadas aos cuidados recebidos na primeira infância, como: quem a acompanhava na hora de dormir? Quem lia histórias? Quem fazia a comida que mais 
gostava? De quem tinha mais medo? Quem te levava na escola? Quando surgia algum problema, quem ajudava? dentre outras, na intenção de detectar as contradições e identificá-las durante as associações livres, pois "[...] nos interessa basicamente - saber o nível de maternagem que recebeu. Por quê? Porque a consciência se organiza segundo o amparo ou o desamparo recebidos" (GUTMAN, 2013, p. 42)

Por outro lado, o discurso do eu iludido ganha relevo porque não há personagens mais importantes ou mais fortes que outros, se um encarnar o papel de doente da família pode se tornar o mais poderoso ao longo de gerações, muitos dependeram de sua enfermidade para sobreviver, e se outro encarnar o papel de valente ou empresário de sucesso não poderá apresentar notícias más para que o doente não tenha um infarto do coração.

Uma das únicas formas de alívio é tomar a decisão de não esperar mais do que nossa mãe teve condições de oferecer, caso tenhamos revisado nossa história e constatado que ela foi uma mãe infantil, mais preocupada consigo mesmo, com seu egocentrismo, com pouquíssima capacidade altruísta de oferecer um lugar em sua vida possível de atenção, carinho e cuidado, porque isso é essencial para uma mãe exercer maternagem para um ser que carece de cuidados indispensáveis.

É fato que o personagem dado por nossos cuidadores mais próximos podem ser nossos cuidadores mais fiéis, nos oferecer a proteção visível e invisível que esperamos na medida em que o apego a um personagem se fará ainda mais necessário quanto maior for o desamparo vivido durante a infância, seja de ordem emocional e afetiva, afinal, tudo o que uma criança necessita é de amor, cuidado e carinho.

Para criar os filhos livres de nossas projeções, torna-se fundamental a permissão para que escolham seus brinquedos preferidos, suas roupas prediletas e principalmente, partir do princípio de que a liberdade irá exigir um olhar suficientemente limpo dos seus pais, o que parece ser uma tarefa complexa diante dos juízos de valores e preconceitos que são transmitidos de geração em geração em nossa atualidade, já que vivemos na chamada sociedade da informação. A autora afirma que as crenças de opiniões pessoais possuem praticamente quase nada de pessoais, na medida em que se encaixam perfeitamente no discurso do eu iludido, 
mesmo que tenhamos acreditado que refletimos sobre tais opiniões, nossas ações no mundo estão reproduzindo e repetindo o que escutamos até cansar durante toda a nossa infância.

Parece bizarro, mas todas as religiões e sistemas morais existentes no mundo não são capazes de desenvolver a capacidade de amar das pessoas, pois todos nós caminhamos pelo mesmo nicho básico e linear, ao qual possuímos enorme dificuldade de nos distanciar, pelo fato de termos ideias comuns que interagem de forma automatizada em relação a quase tudo, à educação dos filhos, à alimentação, à cultura, dentre outras, que por sua vez estão intimamente ligados ao incremento patrimonial.

O patriarcado funciona como organização social há cerca de cinco mil anos ou mais tanto no Oriente como no Ocidente e baseia-se basicamente na submissão, em princípio da mulher em relação ao homem e da criança em relação a adulto. A violência invisível utiliza como ferramenta principal a repressão, pois a criança possui como necessidade básica primordial o contato corporal e emocional permanente com outro ser, e cansamos de ver mães afirmando "é melhor deixá-lo chorar para não ficar mal acostumado" ou mesmo "para que não fique manhoso", é totalmente habitual vermos até médicos afirmando que o lugar da criança é o berço, o carrinho, a cadeirinha e de preferência que durma sozinho. Por isso, feliz é a criança que tem acesso a cama dos pais como seu lugar de refúgio e proteção para acalentar-se de todos os medos que possui.

Quanto ao impulso de encontrar o significado de nossas vidas através da capacidade de atribuir sentidos aos acontecimentos ou às experiências, reprimimos, projetamos, substituímos ou sublimamos formas positivas e negativas de nosso interior em processos psíquicos de autoexpressão para nos adaptarmos à realidade circundante, nossa sombra e identidade constituem essa junção de aspectos positivos e negativos que entram em constante contradição com aquilo que os outros esperam de nós.

Fica nítido o desafio do analista em desmontar o discurso do eu iludido na prática terapêutica que irá exigir, paciência, tato, sensibilidade e treinamento para podermos olhar, enquanto analistas, a tessitura das histórias pessoais dos sujeitos que nos procuram com maior amplitude, as múltiplas necessidades do indivíduo, entendendo-as como necessidades básicas - puramente fisiológicas e relacionadas à respiração do oxigênio, do alimento, do sono e da satisfação sexual - as necessidades 
mais elevadas - como de estabilidade, segurança, amor, pertencimento, contato físico e amizades - e as necessidades mais superiores - como de autonomia, competência, realização pessoal, busca de verdade, criatividade e desejo de justiça.

A metodologia de construção da biografia humana é um trabalho que funciona como terapia familiar, desenvolvido pela argentina Laura Gutman, que escreveu vários livros sobre maternidade, paternidade, vínculos afetivos, desamparo emocional e violência, também dirige um centro de formação em Buenos Aires com destaque à metodologia descrita nesta resenha.

A problemática que se coloca é justamente conseguir chegar ao verdadeiro eu, através da prática e mediação analítica, o que irá exigir o despojamento quase que completo das múltiplas máscaras que fazem parte da própria constituição do sujeito e de sua identidade sendo construída desde o nascimento, sempre confirmada pela aceitação e permissão na relação com o outro. Retirar as nossas máscaras diante dos mecanismos pelos quais aprendemos a nos defender é um enorme desafio analítico no processo terapêutico.

É possível realizar um comparativo entre a metodologia da construção da biografia humana com as perspectivas psicanalíticas freudianas, no sentido de compor a centralidade das práticas analíticas das associações livres que são realizadas pelo analisando/paciente, que trazem consigo durante a realização das cronologias e mapas os seus personagens fantasiados, sendo a memorização da primeira infância o elemento central para a formulação dos mecanismos de defesa e constituição desses personagens, compreendendo e ampliando os cenários completos em meio as contradições intrínsecas da conduta humana. 
RAFAEL DA SILVEIRA

\section{REFERÊNCIAS}

GUTMAN, Laura. O poder do discurso materno: Introdução à metodologia de construção da biografia humana. Trad. Lizandra Magon de Almeida. 4. ed. São Paulo: Ágora, 2013. 
RECEBIDO EM 28/09/2019

ApROVADO EM 10/10/2020

() 2020 Psicanálise \& Barroco em revista

http://www.seer.unirio.br/index.php/psicanalise-barroco/index

revista@psicanaliseebarroco.pro.br

Programa de Pós-Graduação em Memória Social — UNIRIO

Memória, Subjetividade e Criação

www.memoriasocial.pro.br/proposta-area.php 